\title{
Precision Weed Detection using Terrestrial Laser Scanning Techniques
}

\author{
PÉTER RICZU, ATTILA NAGY, ÉVA LEHOCZKY, \\ AND JÁNOS TAMÁS
}

\section{QUERY SHEET}

This page lists questions we have about your paper. The numbers displayed at left can be found in the text of the paper for reference. In addition, please review your paper as a whole for correctness.

Q1: $\quad$ Au: Please provide 3 to 5 keywords for the article.

Q2: Au: Please update reference [Lehoczky et al., 2006] with volume number.

Q3:

$\mathrm{Au}$ : Please update reference [Nagy, 2004] with publisher name.

Q4:

$\mathrm{Au}$ : Please update reference [Pfeifer et al., 2007] with publisher name.

Q5:

Q6: $\mathrm{Au}$ : Please update reference [Roper, 1992] with publisher location.

$\mathrm{Au}$ : Please provide submission dates (received and accepted).

Q7:

$\mathrm{Au}$ : Your Fundref details have been set in your proof. These have been updated from the Original manuscript. Please check and confirm they are correct.

\section{TABLE OF CONTENTS LISTING}

The table of contents for the journal will list your paper exactly as it appears below:

Precision Weed Detection using Terrestrial Laser Scanning Techniques

Péter Riczu, Attila Nagy, Éva Lehoczky, and János Tamás 


\title{
Precision Weed Detection using Terrestrial Laser Scanning Techniques
}

\author{
PÉTER RICZU, ${ }^{1}$ ATTILA NAGY, ${ }^{1}$ ÉVA LEHOCZKY,${ }^{2}$ \\ AND JÁNOS TAMÁS ${ }^{1}$
}

${ }^{1}$ Faculty of Agricultural and Food Sciences and Environmental Management, Institute of Water and Environmental Management, University of Debrecen, Debrecen, Hungary

${ }^{2}$ Institute for Soil Sciences and Agricultural Chemistry, Centre for Agricultural Research, Hungarian Academy of Sciences, Budapest, Hungary

\begin{abstract}
Weeds compete with cultivated plants for nutrients and water in agricultural fields and orchards. Site-specific precision plant protection requires optimal plant-specific pesticide combinations and quantities. The first step in precision weed control is to map and detect weeds. Active and passive remote-sensing tools are available for weed detection. This article presents a study of precision weed detection using three-dimensional terrestrial laser scanning in an apple (Malus domestica) orchard. The laser scanner was able to identify two monocotyledonous (Digitaria sanguinalis, Echinochloa crusgalli) and two dicotyledonous (Galinsoga parviflora, Portulaca oleracea) weed species. In addition to weed identification, weed coverage was also determined using three algorithms. The results indicate that laser scanning has the potential for fast, accurate weed detection and could support the development of a plant-specific, selective, precision weed-control system that reduces water and pesticide use in orchards.
\end{abstract}

\section{Keywords}

\section{Introduction}

Weeds compete with cultivated plants for nutrients, water, and, in some cases, light; thus, weeds strongly influence the profitability of crop and fruit production. In the spring, frost damage is greater on weed-covered sites compared with bare soil (Lipecki 2006) because bare soils absorb more heat during the day. Furthermore, weeds can provide suitable conditions for some orchard pests, and large weeds can shade and severely stunt the growth of young trees in newly planted orchards. Furthermore, weeds growing near the trunks of fruit trees can delay fruit ripening (Roper 1992). In addition, weeds may also have an allelopathic effect on cultivated plants (Lipecki 2006).

It is widely known that weeds are heterogeneously distributed, vary in density, and can forms patches within agricultural fields and horticultural plantations (Nagy 2004; Mortensen, Johnson, and Young 1993); therefore, characterizing and sampling the spatial distribution of weed species are problematic (Dille, Mortesen, and Young 2002).

Received xxxx; accepted xxxx.

Address correspondence to Péter Riczu, Faculty of Agricultural and Food Sciences and Environmental Management, Institute of Water and Environmental Management, University of Debrecen, Böszörményi str. 138, Debrecen, Hungary. E-mail: riczu@ agr.unideb.hu 
Conventional weed scouting is time and labor intensive (Clay and Johnson 1999), and weed coverage is often assumed to be a homogeneous feature on larger agricultural parcels (Nagy 2004). The key to precise weed control involves the accurate detection of weeds, the identification of weed species, and the determination of their spatial distribution.

Most researchers evaluate the spatial variation of weeds using rapid, accurate methods over large areas. Among the most effective tools and methods for identifying and distinguishing the patchiness of weeds are active and passive remote sensing (RS) (Everitt et al. 1995; Kardeván et al. 2005; Lehoczky et al. 2006).

Remote sensing is an effective tool for monitoring weed biomass and often involves calculating vegetation indices from specific spectral bands (Shaw 2005). Most of this type of research has examined arable crops, whereas the determination and identification of weed coverage has been studied less in orchards.

Terrestrial laser scanning (TLS) is a new, active, remote technique that can quickly provide structural information about objects, accurately and cost-effectively, over a large area. A three-dimensional 3D laser scanner analyzes objects and collects data about their shape, structural characteristics, and environment (Heritage and Large 2009; Vosselman and Hans-Gerd 2010). The TLS surveys generate 3D point datasets, termed point clouds. In addition to XYZ spatial coordinates, the points also have intensity values, which represent the reflectance properties of their surfaces. Most studies have demonstrated the utilization of intensity data for the classification and segmentation of TLS data (Pfeifer et al. 2007; Kaasalainen et al. 2010), but the identification of weeds from point clouds is not as thoroughly studied.

\section{Materials and Methods}

The aim of this research was to examine the applicability of TLS for weed mapping and characterization. The TLS surveys were conducted with a Leica ScanStation C10 3D terrestrial laser scanner (Leica Geosystems AG, Heerbrugg, Switzerland). The surveys were conducted in an intensively cropped apple orchard with multiple apple (Malus domestica) varieties (Golden Reinders, Early Gold, Gala Must, and Gala Galaxy) involving drip irrigation and a hail net, and the orchard was located in Pallag, northeastern Hungary.

A 3D laser scanner was used to identify different weed species. The laser scanner used the time-of-flight (TOF) principle for ranging. Based on the time delay between the emitted and reflected parts of the laser light, the spatial position of the measured points and the distance between the points and scanner could be calculated (Beraldin, Blais, and Lohr 2010). The scanner sweeps the examined object with a green (532-nm) laser light, measuring distances of several thousand points per second, resulting in a high-resolution point cloud. The high scan rate (up to $50 \mathrm{kHz}$ ) is possible due to a special hexagonal mirror system, which deflects the course of the laser beam. The constant laser light is effective for detecting plants because the chlorophyll content of leaves is sensitive to green light (Eitel, Vierling, and Long 2010).

One orchard row was surveyed using seven laser scanner location points, which provided seven high-density point clouds. These point clouds were integrated and transformed into a common coordinate system. This integration was derived from a system of tie points, which are high-reflectance surfaces that were set in overlapping parts of the point clouds. The whole point cloud consisted of $27,861,242$ points. Based on the shape and intensity of the point cloud, species-level weed identification was conducted. Each collected point from the laser scanner had an attached intensity value. The intensity values represented the strength of the returned laser pulse. The intensity range was -2047 to +2048 , based 
on calculations using the Leica Cyclone software (Leica Geosystems AG, Heerbrugg, Switzerland), which can recalculate values into real intensities/reflectance values (0-1).

In the study area, two monocotyledonous (hairy crabgrass, Digitaria sanguinalis, and common barnyard grass, Echinochloa crus-galli) and two dicotyledonous (yellow weed, Galinsoga parviflora, and common purslane, Portulaca oleracea) weeds were detected (Figure 1).

Three segmentation methods were used to distinguish the weed species from bare ground and from each other. During segmentation, the point clouds were divided into two subcategories: soil ("segmented soil") and weed ("segmented weed"). The data processing, the unification of the TLS data at different scan stations, and the segmentations were conducted using a Leica Cyclone 8.0. The segmentation methods applied were developed and are owned by Leica; thus, detailed publication of the interpretation of the applied algorithms is not permitted. Therefore, in the following sections, general descriptions are provided.

In the first segmentation, the intensity of the reflected laser beam ("segment point cloud by intensity value") was used to classify the point cloud. This classification was based on training points. The training points represented distinct characteristics of the soil and vegetation. Segmentation of the "near the reference plane" points divided the point cloud based on a reference plane. The reference plane was based on the mean elevation of the soil surface. This algorithm ignored the effect of the microrelief. The so-called "smooth surface" technique represented surface roughness. This algorithm eliminates vegetation from the soil surface for elevation modeling. The first classification method is based
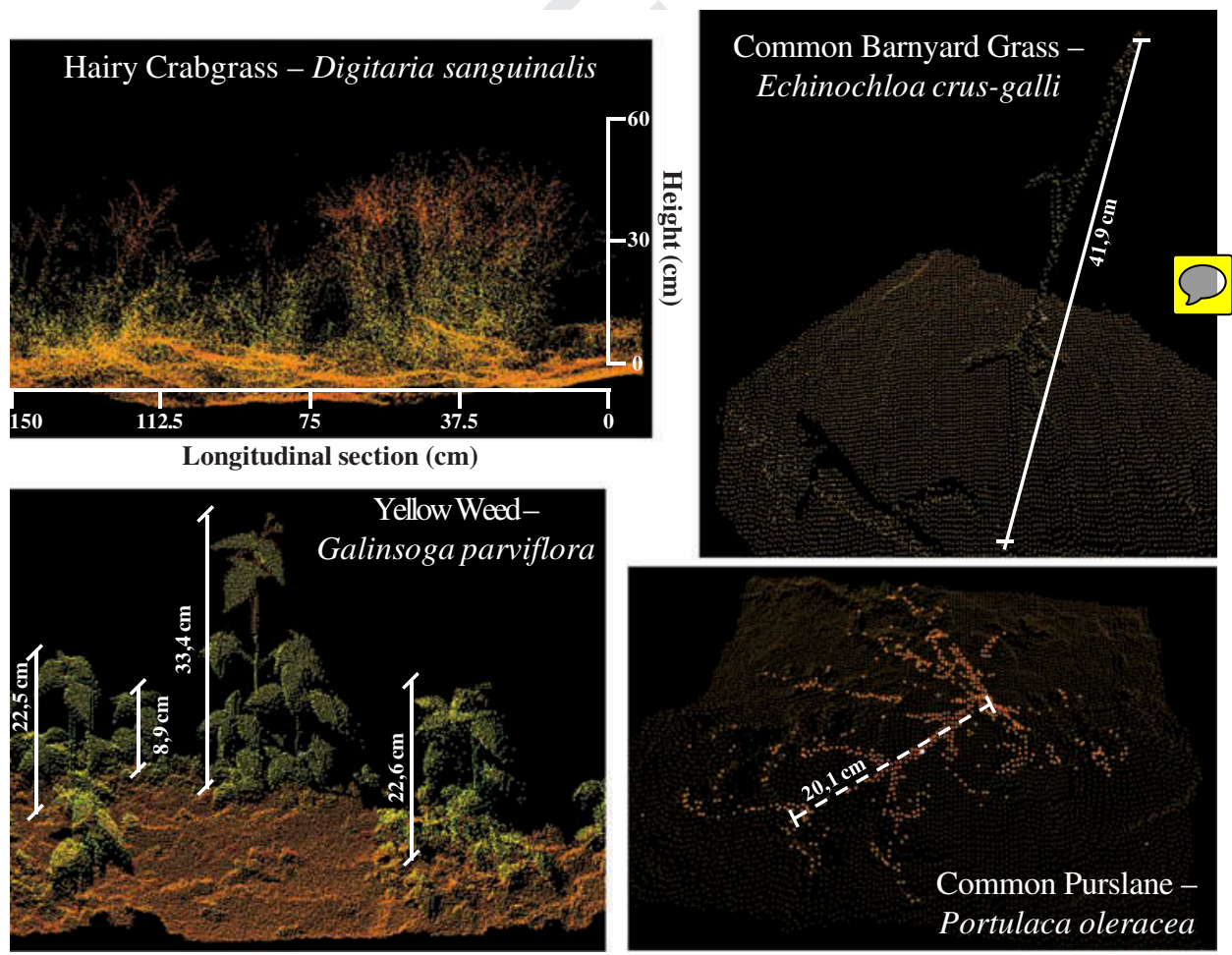

Figure 1. Size of the identified weed species based on the 3D point cloud. 

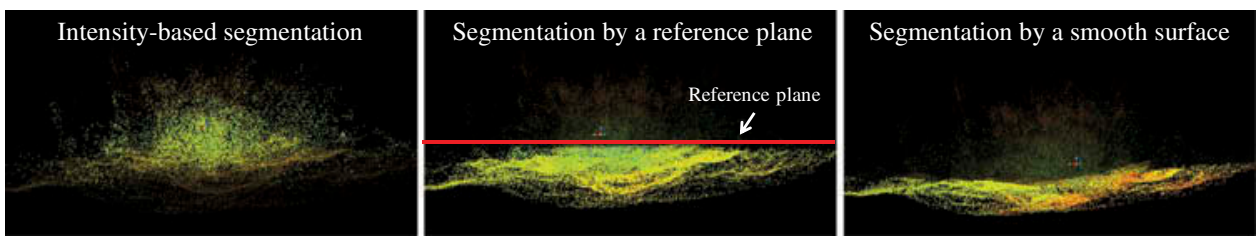

Figure 2. Segmented point cloud of Digitaria sanguinalis by the tree algorithms.

on intensity values, whereas the second and third methods consider only the spatial characteristics (the $\mathrm{X}$ and $\mathrm{Y}$ coordinates and elevation data) of the points for segmentation (Figure 2).

The reliability of the segmentation results was evaluated based on the intensity values. The soil and weed species training-point cloud samples were also used as a reference (hereafter referred to as "reference soil" and "reference weed," respectively) to evaluate the differences in intensity values among the weed species and the soil and to evaluate appropriate methods for distinguishing weeds from soil and from other weed species. The five reference-point clouds represented the characteristics of the soil and the four weed species. Using IBM SPSS 22 software (SPSS Inc., Chicago, IL, USA), Tukey's B variance analysis was used to define the most feasible method for species-level identification.

\section{Results and Discussion}

First, the effectiveness of the intensity values of the reference-point cloud samples for weed identification was examined. Significant differences were detected between the intensity values for soil and for weed species; therefore, using the intensity values for weed identification is deemed reliable (Table 1).

In the case of the "segment point cloud by intensity values" method, the reflected intensity of healthy vegetation was greater than that of the soil surface due to the low absorption of green light by plant tissues. Based on the intensity of the selected training points, the point cloud was segmented into a weed component and a soil component. In many cases, certain vegetation points were classified as soil and vice versa. Furthermore, the intensity values of the inflorescences of the monocotyledonous weeds were problematically similar to the soil intensity values, especially in the case of Digitaria sanguinalis, which had a dry and yellowish inflorescence at the time. Because the stems and leaves of the monocotyledonous weeds had relatively greater average intensity values compared to the dicotyledonous weeds, this classification error did not affect the identification of the monocotyledonous species. In the case of the four weed species, significant differences were detected between the weeds and soil, which suggested that intensity values could be used for 3D database classification. Significant differences were not detected between the intensity values of "reference soil" and "segmented soils" or between "reference weed' and 'segmented weeds"; the intensity method is effective for soil and weed pattern classification. The only exception was Digitaria sanguinalis, because the reference weed contained inflorescence points, but the segmented weeds only contained the points of shoots (Table 1).

Because of surface roughness, the "near the reference plane" technique resulted in classification errors; certain vegetation points were below the reference plane and were categorized as soil. This method provides feasible results for Digitaria sanguinalis, which 


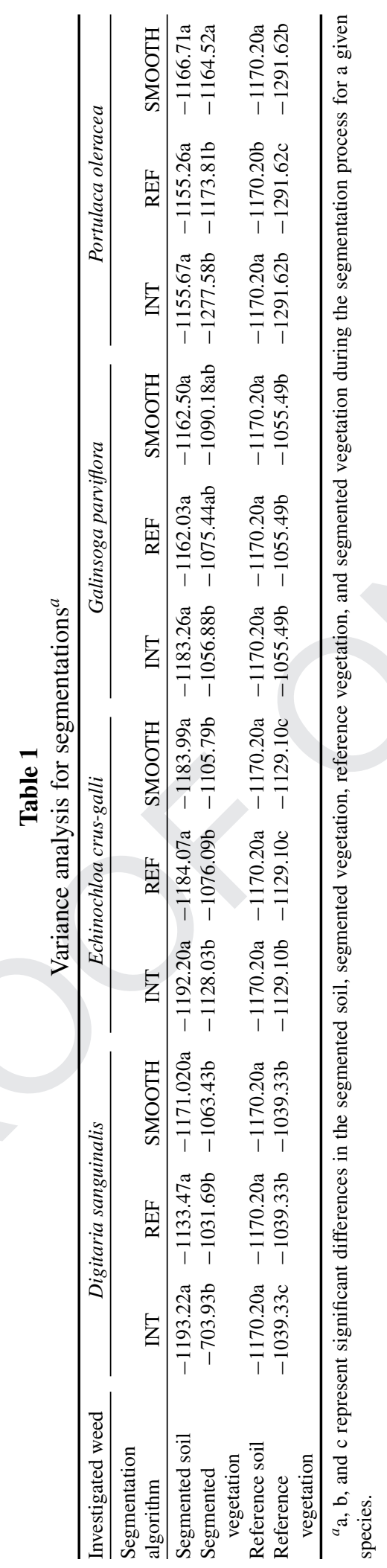


Table 2

Weed identification based on segmentation methods ${ }^{a}$

\begin{tabular}{lccc}
\hline & \multicolumn{3}{c}{ Segmentation methods } \\
\cline { 2 - 4 } Weed species & Intensity & Reference plane & Smooth surface \\
\hline Digitaria sanguinalis & $-703.93 \mathrm{a}$ & $-1031.69 \mathrm{a}$ & $-1063.43 \mathrm{a}$ \\
Galinsoga parviflora & $-1056.88 \mathrm{~b}$ & $-1075.44 \mathrm{a}$ & $-1090.18 \mathrm{ab}$ \\
Echinochloa crus -galli & $-1128.03 \mathrm{c}$ & $-1076.09 \mathrm{a}$ & $-1105.79 \mathrm{~b}$ \\
Portulaca oleracea & $-1277.58 \mathrm{~d}$ & $-1173.81 \mathrm{~b}$ & $-1164.52 \mathrm{~b}$ \\
\hline
\end{tabular}

${ }^{a} \mathrm{a}, \mathrm{b}, \mathrm{c}$, and $\mathrm{d}$ represent significant differences among the weed species within the segmentation process.

was the only weed species for which significant differences were found between the intensity values of "segmented soil" and "segmented weed"; however, there were no differences between the segmented and reference soils and the weed features. For example, the classification seems to be appropriate for Portulaca oleracea selection; however, the "segmented weed" vegetation had similar reflectance values as the "reference soil," and there was no statistical similarity between the "reference weed" and "segmented weed." Some of these problems occurred with Galinsoga parviflora and Echinochloa crus-galli. Thus, this method cannot be used for weed identification.

To avoid the effect of the landscape relief, a "smooth surface" segmentation technique was also tested. Similar results were achieved in the case of the "near the reference plane" technique. The best classification results were detected in the case of Digitaria sanguinalis, but for Portulaca oleracea, the segmentation process was not able to separate the vegetation from the soil. In the case of Galinsoga parviflora, there were no clear segmentation results of soil and vegetation based on significant differences.

In the case of small weeds (heights less than $5 \mathrm{~cm}$ ) (e.g., Portulaca oleracea), only segmentation by intensity values divided the point cloud into real soil and real vegetation categories as the segmented and reference soils, and vegetation was not significantly different from the other cases.

After assessing the elimination of weeds from the soil patterns, the selection possibilities of a single weed species were also studied to provide species-specific weed identification (Table 2). The segmentation algorithms described earlier and the differences among the segmented weeds were examined. The best weed identification results were generated from the intensity values. Based on the intensity values, all of the weed species were identified; the other methods were not able to discriminate between the weed species. The intensity values were suitable for separating weeds from soil and for differentiating weed species; therefore, they can be utilized in species-specific precision weed control.

\section{Conclusions}

The 3D laser scanner technology is rarely used for weed detection. Based on the shape of the point clouds, 3D laser scanning is an appropriate tool for the species-level differentiation and identification of the four weed species examined in this study. Segmentation based on intensity values is appropriate for the identification of monocotyledonous (Digitaria sanguinalis, Echinochloa crus-galli) and dicotyledonous (Galinsoga parviflora, Portulaca 
oleracea) weed species. Therefore, laser scanning can potentially detect weeds quickly and accurately and could support the development of water- and herbicide-saving and weed-specific selective precision weed-control systems in orchards.

\section{Acknowledgments}

The University of West Hungary, Faculty of Geoinformatics, conducted the laser scanning. The authors thank Attila Váradi from Leica Geosystems Hungary Ltd. for his assistance in the Leica software processing.

\section{Funding}

This research was realized in the framework of TÁMOP 4.2.4. A/2-11-1-20120001 National Excellence Program: Elaborating and Operating an Inland Student and Researcher Personal Support System. The project was subsidized by the European Union and cofinanced by the European Social Fund. This publication was supported by the OTKA project K 105789.

\section{References}

Beraldin, J.-A., F. Blais, and U. Lohr. 2010. Laser scanning rechnology. In Airborne and terrestrial laser scanning, ed. G. Vosselman and M. Hans-Gerd, 1-42. Boca Raton, FL: CRC Press.

Clay, S. A., and G. Johnson. 1999. Scouting for weeds: Site-specific management guidelines (SSMG15). Norcross, GA: Potash and Phosphate Institute.

Dille, J. A., D. A. Mortesen, and L. J. Young. 2002. Predicting weed species occurrence based on site properties and previous year's weed presence. Precision Agriculture 3 (3): 193-207. doi:10.1023/A:1015596518147

Eitel, J. U. H., L. A. Vierling, and D. S. Long. 2010. Simultaneous measurements of plant structure and chlorophyll content in broadleaf saplings with a terrestrial laser scanner. Remote Sensing of Environment 114 (10): 2229-37. doi:10.1016/j.rse.2010.04.025

Everitt, J. H., G. L. Anderson, D. E. Escobar, M. R. Davis, N. R. Spencer, and R. J. Andrascik. 1995. Use of remote-sensing for detecting and mapping leafy spurge (Euphorbia esula). Weed Technology 9 (3): 599-609.

Heritage, G. L., and A. R. G. Large. 2009. Laser scanning for the environmental sciences. New York: Blackwell.

Kaasalainen, S., H. Niittymaki, A. Krooks, K. Koch, H. Kaartinen, A. Vain, and H. Hyyppa. 2010. Effect of target moisture on laser scanner intensity. IEEE Transactions on Geoscience and Remote Sensing 48 (4): 2128-36. doi:10.1109/TGRS.2009.2036841

Kardeván, P., P. Reisinger, J. Tamás, and A. Jung. 2005. Remote sensing of common ragweed, part I: Enhancing classification effectivity of remote sense pictures by using DGPS for representative spectra of Ambrosia artemisiifolia L. Hungarian Weed Research and Technology 6 (2): 53-67.

Lehoczky, É., J. Tamás, A. Kismányoki, and P. Burai. 2006. Comparative study of fertilization effect on weed biodiversity of long term experiments with near field remote sensing methods. Journal of Plant Diseases and Protection 801-7.

Lipecki, J. 2006. Weeds in orchards: Pros and contras. Journal of Fruit and Ornamental Plant Research 14 (3): 13-18.

Mortensen, D. A., G. A. Johnson, and L. J. Young. 1993. Weed distribution in agricultural fields. In Proceeding of soil specific crop management, ed. P. C. Robert and R. H. Rust, 113-24. Madison, WI: ASA. 
Nagy, S. 2004. Development of weed survey methods to planning precision weed control. Ph.D. thesis, Mosonmagyaróvár, Hungary.

Pfeifer, N., P. Dorninger, A. Haring, and H. Fan. 2007. Investigating terrestrial laser scanning intensity data: Quality and functional relations. In Eighth Conference on O3D, 328-37. Zurich.

Roper, T. R. 1992. Orchard-floor management for fruit trees, 1-4. University of Wisconsin Extension.

Shaw, D. R. 2005. Remote sensing and site-specific weed management. Frontiers in Ecology and the Environment 3 (10): 526-32. doi:10.1890/1540-9295(2005)003[0526:RSASWM]2.0.CO;2

220

elman, G., and M. Hans-Gerd. 2010. Airborne and terrestrial laser scanning. Dunbeath, Caithness: Whittles. 